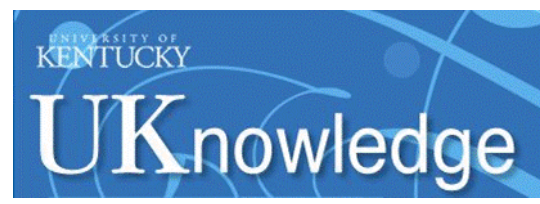

University of Kentucky

UKnowledge

\title{
Transcriptional Correlates of Proximal-Distal Identify and Regeneration Timing in Axolotl Limbs
}

\author{
S. Randal Voss \\ University of Kentucky, srvoss@uky.edu \\ David Murrugarra \\ University of Kentucky, murrugarra@uky.edu \\ Tyler B. Jensen \\ Northeastern University \\ James R Monaghan \\ Northeastern University
}

Follow this and additional works at: https://uknowledge.uky.edu/neurobio_facpub

Part of the Anatomy Commons, Biochemistry Commons, Comparative and Evolutionary Physiology

Commons, Neuroscience and Neurobiology Commons, and the Pharmacology, Toxicology and

Environmental Health Commons

Right click to open a feedback form in a new tab to let us know how this document benefits you.

\section{Repository Citation}

Voss, S. Randal; Murrugarra, David; Jensen, Tyler B.; and Monaghan, James R, "Transcriptional Correlates of Proximal-Distal Identify and Regeneration Timing in Axolotl Limbs" (2018). Neuroscience Faculty Publications. 54.

https://uknowledge.uky.edu/neurobio_facpub/54

This Article is brought to you for free and open access by the Neuroscience at UKnowledge. It has been accepted for inclusion in Neuroscience Faculty Publications by an authorized administrator of UKnowledge. For more information, please contact UKnowledge@lsv.uky.edu. 


\section{Transcriptional Correlates of Proximal-Distal Identify and Regeneration Timing in Axolotl Limbs}

\section{Digital Object Identifier (DOI)}

https://doi.org/10.1016/j.cbpc.2017.10.010

\section{Notes/Citation Information}

Published in Comparative Biochemistry and Physiology Part C: Toxicology \& Pharmacology, v. 208, p. 53-63.

(C) 2017 Elsevier Inc. All rights reserved.

This manuscript version is made available under the CC-BY-NC-ND 4.0 license

https://creativecommons.org/licenses/by-nc-nd/4.0/.

The document available for download is the author's post-peer-review final draft of the article. 


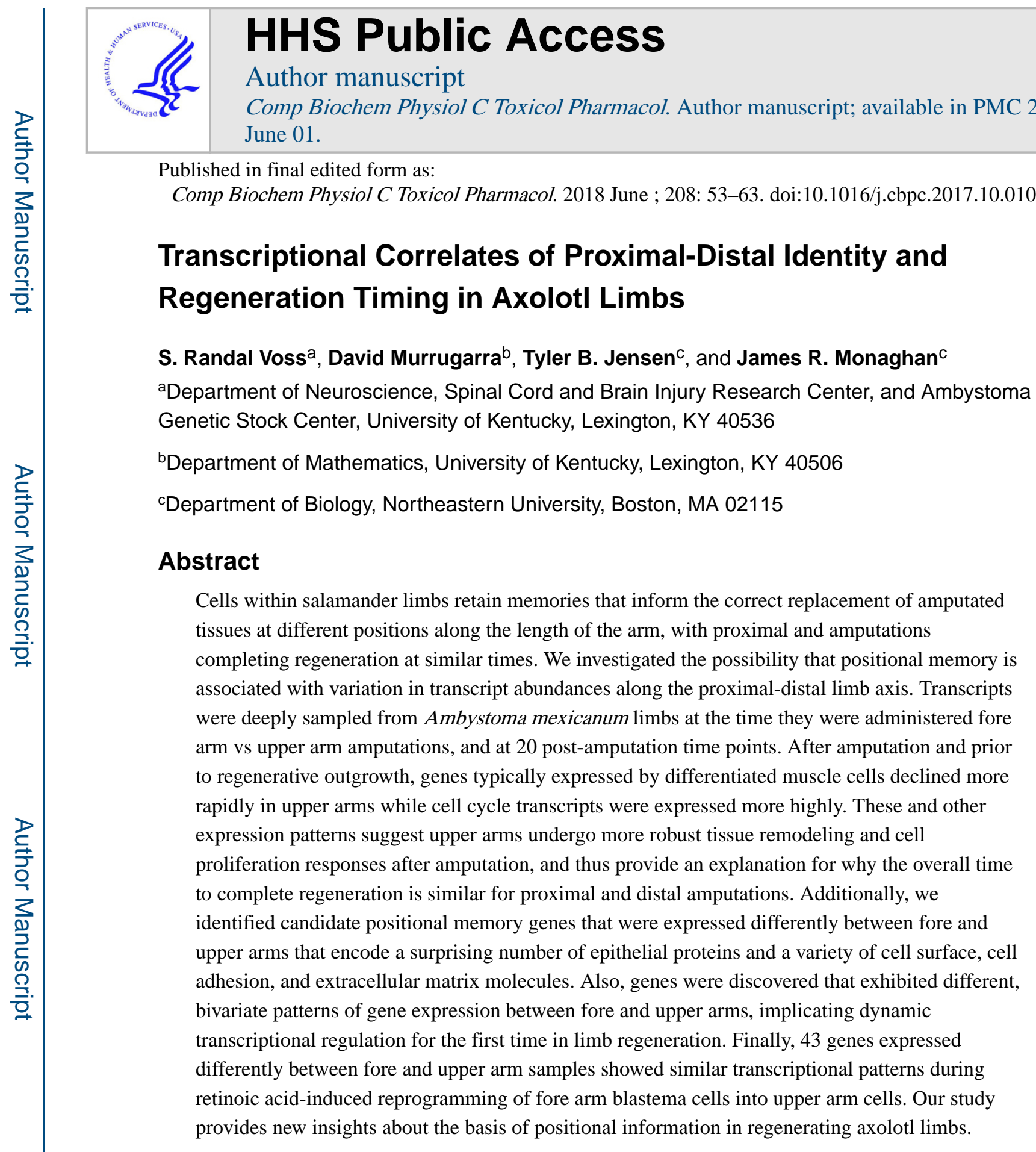

\section{Keywords}

Axolotl; limb regeneration; transcription; positional memory

Corresponding Author: S. Randal Voss, Department of Neuroscience, Spinal Cord and Brain Injury Research Center, Ambystoma Genetic Stock Center, University of Kentucky, Lexington, KY 40536, 859-257-9888, srvoss@uky.edu.

Publisher's Disclaimer: This is a PDF file of an unedited manuscript that has been accepted for publication. As a service to our customers we are providing this early version of the manuscript. The manuscript will undergo copyediting, typesetting, and review of the resulting proof before it is published in its final citable form. Please note that during the production process errors may be discovered which could affect the content, and all legal disclaimers that apply to the journal pertain. 


\section{Introduction}

Salamander limb regeneration provides an excellent model to identify endogenous mechanisms of tissue repair that might one day be translated to humans. A fundamental question in the limb regeneration field concerns the basis of positional information in cells along the proximal distal axis (McCusker and Gardiner, 2014; Bryant and Gardiner, 2016). How do limb cells that survive an amputation injury orchestrate a reparative response that reforms the appropriate distal structures? Seemingly, progenitor cells have position-specific information prior to amputation or gain this information during regeneration. The basis of this information maybe a quantitative property of cells or components of the nearby extracellular environments that cells create and maintain. For example, retinoic acid treatment of a distal limb stump reprograms blastema cells to a proximal positional identity (Maden, 1982), likely by altering gene expression (Nguyen et al., 2017). Also, when distal blastemal cells are grafted into proximal blastemal sites, their cellular movements suggest positional information is communicated via cell surface proteins (da Silva et al., 2002; Echeverri and Tanaka., 2005; Kumar et al., 2007). Additionally, positional information may correlate with other cell properties including cell adhesion, composition of extracellular environments, and bioelectricity, which likely regulate cell fate decisions during proximaldistal limb regeneration (Levin, 2014; McCusker et al., 2015; Phan et al., 2015).

Somewhat associated with the question of positional memory concerns the rate at which regeneration proceeds along the proximal-distal axis. The time from amputation to the completion of regeneration is similar regardless of where an amputation is performed along the limb axis (Iten and Bryant, 1973; Stocum, 1980). Surprisingly, limbs that are amputated at different anatomical positions pass through stages of regeneration at the same time, but more overall growth occurs in proximal amputations to replace the greater amount of missing tissue. In other words, it takes a similar amount of time for a salamander to regenerate an elbow, fore arm, and hand after an upper arm amputation as it does to regenerate a hand after an amputation through the wrist. Why the time to complete regeneration evolved to be similar along the limb axis is curious enough, but equally curious is the nature of the mechanisms that alter regeneration to achieve a similar offset timing.

Here we investigate the possibility that positional memory and regeneration timing are properties of transcriptional control. We reasoned that cells sampled from different anatomical positions at the time of amputation and during regeneration would express different transcripts associated with positional information and regeneration timing. Further, we reasoned that by filtering these genes against an existing list of genes that showed differential expression in response to retinoic-acid treatment (Nguyen et al., 2017), we would identify candidates for positional information. Within these contexts, we report differently expressed genes, highlighting candidates that are most likely to provide new insight about the basis of positional information and regeneration timing in axolotl limbs. 


\section{Materials and methods}

\subsection{Gene expression analysis}

The experimental design and methods for collecting tissues, isolating RNA, and performing microarray analysis were previously detailed in Voss et al. 2015 (Figure 1). That study generated comprehensive gene expression datasets for axolotl fore and upper arm regeneration, but only presented results of the fore arm regeneration dataset. Here, we use both datasets to identify genes that were expressed differently between fore and upper arm tissue samples at the time of amputation (Day 0: D0) and during specific intervals of time during the first 28 days of limb regeneration: D0-0.1, D1-D2, D3-D9, D10-D16, D16-D20, D20-24, and D24-D28. Day 0 consisted of a $1 \mathrm{~mm}$ thick heterogenous cross section of limb across the amputation plane. Post-amputation, tissue was collected within $1 \mathrm{~mm}$ of the distal blastemal tip. For each time interval, the average expression difference was calculated on a gene-by-gene basis between fore and upper arm replicate samples. All genes that exhibited a $>1.0 \log 2$ average expression difference were retained for gene enrichment analysis using Panther Gene Expression tools (Mi et al., 2013), or manual curation using literature mined from Gene and PubMed databases at the National Center for Biotechnology Information (NCBI). GO terms were reported if they met a Bonferroni corrected p-value $<0.05$, as implemented in the Panther statistical overrepresentation test. The fore and upper arm data are available in the Gene Expression Omnibus at NCBI.

\subsection{Immunohistochemistry}

Experimental procedures involving axolotls were approved by IACUC of Northeastern University under protocol number 15-1244R. Amputated limbs were collected from animals $6 \mathrm{~cm}$ in total length (RRID:AGSC_100J) and fixed overnight in 4\% paraformaldehyde at $4{ }^{\circ} \mathrm{C}$. Limbs were then cryoprotected in $30 \%$ sucrose and cryosectioned at $30 \mu \mathrm{m}$ from each the center of the proximal limb segment and distal limb segment. Limbs sections were stained for myosin heavy chain (DSHB MF-20) overnight at $4{ }^{\circ} \mathrm{C}$ and muscle and bone were quantified as a fraction of the total area of the tissue section. Area was quantified using FIJI/ ImageJ (Schindelin et al 2012) to determine the relative fraction of pixels contained within each region.

\section{Results and Discussion}

\subsection{Identification of differently expressed genes}

Previously, we reported on a highly-powered, transcriptional study of axolotl fore arm regeneration. In that study, tissue was collected at the time of amputation and at 19 postamputation time points during the first 28 days of regeneration, using 10 biological replicates for each time point. To complement this body of work, we report on an equally powered dataset based on an upper arm amputation. We used fore and upper arm data to identify genes expressed differently at the time of amputation and during regeneration, as these genes might provide perspective on the molecular basis of positional information. A comprehensive description of the upper arm data will be presented elsewhere; here, we focused attention on transcriptionally and biologically significant time intervals that were discovered in the previous study of axolotl fore arm amputation. The time intervals were: 0 
0.5 DPA (initial burst of transcription), 1-2 DPA (phase of decreasing transcription), 3-9 DPA (pre-bud stage), 10-16 DPA (early bud stage), 16-20 DPA (medium bud stage), 20-24 DPA (late bud stage), and 24-28 DPA (pallet stage). Quality control analyses found the 1216 DPA upper arm samples to be outliers as all gene expression estimates for microarray probe sets were reduced in magnitude relative to all other samples (Supplemental File 1). These samples and the corresponding fore arm samples were removed and thus the 10 DPA and 18-20 DPA interval were investigated to identify differently expressed genes. Preliminarily, we investigated the utility of several distance metrics (Kullback-Liebler divergence, Euclidean distance L1, and the Bhattacharyya distance) to identify genes with divergent expression estimates between the fore and upper arm datasets, before deciding to focus on genes with $>1.0 \log 2$ average expression difference in transcript abundance. This conservative approach identified genes with large expression differences between the fore and upper arm datasets, and included high variance genes with large standard deviations of mean expression. In several cases, high variance genes showed bivariate and not continuous expression, implicating dynamic temporal expression for the first time in limb regeneration. Overall, 584 genes (Supplemental File 2) were identified and these significantly enriched Protein Class, Biological Process, Cellular Component, Molecular Function, and Reactome Network Gene Ontology terms (Table 1). Below we present and discuss genes and GO terms in the temporal order of their discovery.

\subsection{Comparison of Bone and Muscle Anatomy in Fore and Upper Arms}

Progenitor cells in the axolotl limb are poised to regenerate appropriate distal tissues, regardless of where an amputation is performed. This suggests that limb cells contain positional information prior to injury, however it is difficult to know if differences discovered along the proximal-distal limb axis are anatomical or positional in nature. For example, fore and upper arms both contain skeletal muscle and bone, but the muscles and bones are different between these limb segments and therefore may contribute different cell proportions when sampled for gene expression analysis (Pantalacci et al., 2017). To gain insight about anatomical differences, we sectioned fore and upper arms and used immunological staining to quantify the relative proportion of muscle and bone tissue. The relative cross-sectional area of bone but not muscle differed significantly between fore and upper limbs (Fig. 2). Thus, proximal-distal expression differences were somewhat expected for bone and cartilage-associated genes, but not muscle.

\subsection{Genes expressed differently at the time of amputation}

Most of the genes that were expressed differently at the time of amputation (Supplemental File 2) are typically expressed in differentiated muscle cells, including a diversity of myosins and myosin-associated proteins that enriched muscle contraction, muscle organ development, and cytoskeletal GO terms (e.g. calponin 1, crystallin alpha B, g proteincoupled receptor 37-like 1, heat shock protein b1, myosin binding protein C1-3, myosin binding protein $H$, myosin heavy chains $1-4,6,7 b, \& 8$, myosin light chains $1-4$, myosin light chain, phosphorylatable, myosin 18b, myomesin $1 \& 2$, small muscle protein X-linked, tropomodulin 1, troponins 1, 2, c1, t1, \& t3, tropomysins 1, 2, \& 3, triadin, titin). Transcripts for these muscle-associated genes were more abundant in fore arm at the time of amputation (Fig. 3). This suggests that basal transcriptional activity is higher in fore arm muscle because 
the proportion of muscle tissue did not differ significantly between upper and lower limbs. After D0, muscle-associated genes decreased in both fore and upper arms through D16, but the initial decrease (D0-D0.5) was steeper in upper arm samples. This pattern of declining transcript abundance was described earlier (Monaghan et al., 2009; Voss et al., 2015). The Voss et al study (2015) noted that the pattern was highly correlated across muscle-associated genes within tissue replicates, suggesting a mechanism that coordinately regulates transcription within muscle cells as they undergo reprogramming or cell death, and/or histolysis at the tissue level. Consistent with the idea of cell death, caspase 7(casp7) was expressed more highly in upper arm samples before and after amputation, suggesting differential muscle cell death in proximal versus distal amputations within the first day postamputation. However, the differential expression of SET and MYND domain containing 1 (smyd1), a regulator of end stage muscle differentiation and myogenesis, persisted until day 9 , suggesting proximal-distal differences in muscle satellite cell pools during the first 9 days of regeneration. These expression patterns may explain why muscle-associated genes showed a steeper decline after amputation in upper arm samples, as rapid changes to muscular composition after cell death and satellite cell pools would yield the patterns observed. Moreover, more rapid histolysis of muscle tissue and other components of the injury environment in upper arm amputations may explain why the overall time to complete regeneration is similar, regardless of where an amputation is performed (Iten and Bryant, 1973; Stocum, 1980).

If positional information is present in cells prior to amputation, this might be reflected in the differential expression of transcription factors that regulate cell identity. The enrichment analysis suggested that our overall list of 584 genes included significantly fewer DNAbinding proteins than would be expected by chance sampling given the number represented on the microarray (Bonferoni corrected probability $=9.88 \mathrm{E}-03$ ). However, we note that fos proto-oncogene (fos) and cysteine rich angiogenic inducer 61 (cyr61) showed higher initial expression in fore arms at the time of amputation, and the expression profiles of these genes during regeneration were mirrored by other early immediate genes (Fig. 4). Voss et al 2015 highlighted the immediate early genes as an example of dynamic, highly coordinated gene expression across the entirety of limb regeneration. While these genes mostly showed the same dynamic pattern of expression in fore and upper arms, it is possible that small $(<2$ fold expression difference) but consistent differences in transcription factor abundances (e.g. meis homeobox 2 - meis2, homeobox A13 - hoxa13) may instruct different proximal-distal positional identities during regeneration (Fig. 4). meis 2 and hoxa13 are known to specify proximal and distal progenitor cell identities, respectively, during limb development and regeneration.

Positional information may also be conferred by proteins that mediate cell-cell and cellextracellular matrix adhesion, or genes whose products constitute, organize, and regulate properties of the extracellular environment. Genes that fit these categories were expressed differently between fore and upper arms at the time of amputation (Fig. 5). Genes expressed more highly in upper arm encode proteins that regulate cytoskeletal organization (ras homolog family member a) and extracellular signaling (galectin 1, galectin 3, galectin 8, mucin 19, brevican, periostin, chordin-like 1). We note that chordin-like 1 (chrdl1) was also identified by Bryant et al. (2017) as proximally enriched during axolotl limb regeneration. A 
greater number of genes were expressed more highly in fore arm samples, and several of these encode proteins associated with cartilage (collagen 9a1, collagen 9a2, collagen $9 a 3$, cap-gly domain containing linker protein 1, epiphycan, lectin 1, matrilin 1); this may reflect the greater relative contribution of bone and cartilage tissue to fore arm samples. Cell adhesion (thrombospondin 4, c-type lectin 3a) and extracellular matrix (ECM) (mucin 2, uromodulin, placenta expressed transcript 1, otospiralin, tectorin alpha, matrilin 4) genes were also expressed more highly in fore arm samples. We noticed that several of the ECM genes encode Van Willebrand and zona pellucida domains typical of gel and filament forming glycoproteins. These include three presumptive uromodulin (umod) paralogs that were all expressed more highly in fore arm, fc fragment of $\mathrm{Ig} G$ binding protein which was expressed more highly in upper arm, and two presumptive tectorin alpha parlogs, one expressed more highly in fore arm and the other in upper arm. Moreover, these genes were also expressed differently during regeneration. While gel and filament forming glycoproteins are generally thought to coat epithelial surfaces as a defense against pathogens, their differential expression along the proximal distal axis may affect how epithelial cells signal to underlying mesenchymal cells during regeneration. Also, as components of the wound environment, they may provide persistent and reliable cues to progenitor cells during regeneration. We note that umod and thyroid hormone down-regulated protein 20 (thd120) (Fig. 5) were expressed differently across the entirety of limb regeneration (excepting 10 DPA) and are known to be expressed in amphibian epithelia (Furlow et al., 1997; Page et al., 2009).

In concluding this section, we report a novel finding that was revealed by our deep sampling of fore and upper arm tissues. Bivariate gene expression was discovered among replicate samples at the time of amputation and during regeneration (Fig. 6). The different estimates of gene expression among replicates at each time point capture genes as either highly or lowly expressed, placenta expressed transcript 1 (plet1) exhibited a trivariate pattern of expression. We note that expression values for these genes did not co-vary within replicates; thus, it's difficult to attribute these complex expression profiles to age, body size, or sexrelated differences among the samples, and we note that all samples were collected at the same time of day. These data show for the first time that genes may exhibit sustained, dynamic regulation under both homeostatic conditions and during limb regeneration. Four (axo24465-r_at, axo31318-r_at, axo31384-f_axo26877-f_at) of 15 bivariate genes are novel to axolotl because they do not align to reference proteins in NCBI databases. The other bivariate genes include: 1) three members of the Ly6/uPAR gene family proteins (gpihbp1, psca, pinlyp), 2) a cytochrome p450 (cyp2a13), 3) a Xenopus laevis lectin (fucolectin), 4) a ubiquitin ligase (herc4), 5) a sarcoplasmic reticulum $\mathrm{Ca}(2+)$-ATPase (sIn), 6) a transcription elongation factor (tcea2), 7) an immunological cell marker (mpeg1), 8) an uncharacterized protein (c17orf67), and 9) a cell surface marker (plet1) that exhibits a dynamic, biphasic transcriptional profile in providing cues to direct trophoblast stem cell differentiation (Murray et al., 2016). Although the significance of temporally, dynamic expression patterns is unclear, these data suggest a need to consider more than absolute transcript levels when prioritizing candidate genes. 


\subsection{Genes expressed differently immediately after limb amputation}

Many of the genes that were expressed differently between fore and upper arm at the time of amputation were also expressed differently during regeneration. Many additional muscleassociated genes were expressed differently after amputation, as were ECM and cartilageassociated genes that were more highly expressed in fore arms (e.g. chrdl1, umod, thdl20, matn4, lect1, and col9a3 in Fig. 5). Considering all 584 genes, the correlation of $\log 2$ fold difference between upper and fore arm D0 and DPA0-DPA0.5 samples was $r=0.87$, and between D0 and DPA1-DPA2 samples $r=0.67$. Thus, initial gene expression differences between un-amputated fore and upper arms were largely maintained during the early wound healing response. A few signaling pathway genes were more highly expressed in fore arms during this time, including connective tissue growth factor (ctgf), transforming growth factor beta 2(tgfb2), fibroblast growth factor receptor like 1 (fgfrl1), and dual oxidase 1 (duox 1 ), a gene known to participate in appendage regeneration in $X$. laevis and zebrafish (Ferreira et al., 2016; Rieger and Sagasti, 2011; Niethammer et al., 2009).

\subsection{Genes expressed differently between 3-9 DPA}

Voss et al. (2015) discovered a second pulse of gene expression between DPA2-3 in fore arm samples that was enriched with genes encoding cell cycle proteins. Cell cycle genes were expressed more highly in upper limbs from D0-3 DPA and plateaued at an earlier time relative to fore arm samples (Fig. 7). Thus, not only does muscle tissue appear to be remodeled earlier in upper arms, the transcriptional profiles of cell cycle-associated genes in upper arms suggest an earlier and more robust gene expression response after injury. Although cell proliferation is generally thought to reflect the expansion of progenitor cells during regeneration, transcription of cell cycle genes very early in the wound-healing process may also be associated with the proliferation of immunological cells or epithelial cells that form the wound epidermis. The thin epithelium covering the amputated limb thickens and matures to form a specialized wound epithelium that secretes signaling molecules (e.g fibroblast growth factors) to stimulate the proliferation of underlying progenitor cells, however this does not occur until 10 DPA (Voss et al., 2015). A more robust cell cycle transcriptional response in the maturing wound epithelium would increase the rate of wound healing in upper arms, especially if this were coupled to metabolic mechanisms that provide energy to fuel cell proliferation. Indeed, lipase c (lipc), a hepatic enzyme that hydrolyzes triglycerides and mediates the uptake of lipoproteins, and a mitochondrial enzyme (3-hydroxy-3-methylglutaryl-CoA synthase 2 - hmgcs2) that catalyzes the first step of ketogenesis to provide lipid-derived energy, were expressed more highly in upper arms (Fig. 7).

In addition to cell proliferation, the 3-9 DPA interval is an important preparative phase for subsequent limb bud outgrowth. During this time, damaged tissue and the ECM undergo remodeling. Several tissue remodeling matrix metalloproteinases (MMPs: mmp1, mmp3, mmp8, mmp10) exhibited higher expression in fore arms (Fig. 7). MMPs are known to regulate cell-cell and cell-extracellular matrix interactions and were first discovered in amphibians undergoing dramatic tissue remodeling events during metamorphosis (Gross and Lapiere, 1962). Studies of axolotls have demonstrated the necessity of MMPs for successful limb regeneration (Santosh et al., 2011) and mammalian studies have shown that MMPs may 
be released by chondrocytes (Bord et al., 1998). Thus, higher expression of MMPs in fore arms (Supplemental File 2) may reflect a relatively higher proportion of chondrocytes and the associated need to remodel relatively more bone tissue to achieve a permissive environment for progenitor cell proliferation. We note that this interpretation maybe too simplistic because ctsk, an osteoclast-specific cysteine proteinase that is integral to bone remodeling, was expressed more highly in upper arms that contained relatively less overall bone mass. The higher expression of cathepsin $k$ (ctsk) may represent another example where transcription is regulated (via osteoclast recruitment or $c t s k$ transcription) to be higher in upper arms to facilitate rapid tissue histolysis.

Finally, we note three genes that diverged during the 3-9 DPA interval and maintained expression differences throughout limb regeneration. desmoglein 4 (dsg4) is a desmosomal cadherin that mediates cell-adhesion in epithelia, while avidin (avd) is a biotin-binding molecule that is highly expressed during newt lens regeneration (Sousounis et al., 2013). Keratin intermediate filaments are key components of the cytoskeleton of cells, but even as they support cellular rigidity and stability, they also perform roles in cell adhesion and migration (Velez-delValle et al., 2016). Four different probe-sets for keratin 5 (krt5) exhibited different temporal patterns; sequence comparisons suggest these probe-sets correspond to different axolotl krt5 paralogs. The expression profile for krt5-axo06032 showed that it was up-regulated during the 2-3 DPA transcriptional pulse in fore and upper arms, but expression increased more rapidly and achieved highe $r$ levels in fore arm samples. $k r t 5$ is a marker of basal and progenitor cells in mammalian epithelial tissue (Knox et al., 2010) and its expression is affected by retinoic acid (see below). We speculate that variation in $d s g 4$ and $k r t 5$ expression would alter cellular adhesive properties along the proximaldistal axis, conferring different structural identities and properties to cells that might in turn instruct positional information.

\subsection{Genes expressed differently at 10 DPA}

The 10 DPA time point was identified by Voss et al. (2015) as the most important transition point in the limb regeneration program, marking the time when the limb bud begins to grow out under the influence of proliferating blastema cells. Here we highlight several genes associated with epithelia that were expressed more highly in fore arm samples (Fig. 8). cathelicidin (camp) is an epithelial derived peptide which in mammals has multiple innate immune functions including antimicrobial host defense, chemotaxis of immunological cells, and wound repair (Bals et al., 1998). epiplakin 1 (eppk1) plays a role in cytoskeletal organization by crosslinking intermediate filaments (e.g. keratins) to microfilaments, microtubules, and cell-adhesion molecules. epithelial membrane protein 1 (empl) has primarily been studied within the context of cancer biology where it is known to affect cell proliferation (Aries et al., 2014). Finally, keratin 14/17-like shows identity to vertebrate krt14 and krt17, the latter of which is known to be expressed in axolotl wound epidermis during regeneration (Moriyasu et al., 2012), and in this study, krt17 was highly up-regulated upon amputation in both fore and upper arms. Both krt14 and krt17 have been associated with basal stem cell progenitors in mammalian epithelia (Stellmach et al., 1989). The sustained differential expression of epithelial genes during limb bud outgrowth likely confers different structural properties to proximal versus distal epidermis. 


\subsection{Genes expressed differently between 18-28 DPA}

Two additional pulses of transcriptional change in fore arms were identified by Voss et al. (2015), the first marking the transition from medium bud to late bud (18-20 DPA) and the second marking the transition from late bud (22-24 DPA) to pallet. While genes encoding a variety of functions were identified for the 18-20 DPA pulse, genes from the 22-24 DPA pulse were enriched for cholesterol synthesis, which is required for normal patterning of bone during limb development (Schmidt et al. 2009). Only two cholesterol pathway genes ( squalene epoxidase, methylsterol monooxygenase 1) were expressed differently suggesting conservation of this aspect of limb patterning between fore and upper limbs. We do however note that a few genes identified for the 18-20 DPA (fos, cyr61, eppk1) and 22-24 DPA (fibroblast growth factor binding protein 1, keratin 12, prostate stem cell antigen) pulses in fore arm did not show the same pattern of expression in upper limb. All of these genes were identified as differentially expressed between upper and lower arms at early time points in this study and thus maybe informative for understanding persistent proximal-distal cues during regeneration.

We highlight several additional gene expression differences between fore and upper arm samples that were observed between 18-28 DPA. TRPM8 channel associated factor 1 (tcaf1), leptin (lep), forkhead box $c 1$ (foxc1), and $t$-box 5 ( $t b \times 5)$ were expressed more highly in upper arms samples during this time (Fig. 9). tcaf1 is a modulator of TRPM8, a calcium ion channel that functions as a cold receptor in mammals. TRPM8 appears to maintain homeostatic conditions in the epidermis by regulating keratinocyte proliferation and differentiation (Bidaux et al., 2016). Studies of zebrafish limb and heart, and axolotl limb regeneration, have shown lep to be highly up regulated upon injury (Kang et al., 2016; Voss et al., 2015). We observed a similar up regulation of lep in fore and upper arms at 0.05 DPA and then a similar decrease in expression until 10 DPA. However, after this time lep decreased linearly in fore arms but levels remained relatively high in upper arms. If lep is mitogenic in axolotl, its differential expression between fore and upper arm samples might adjust progenitor cell proliferation relative to the proximal-distal location of amputation. foxc1, a forkhead family transcription factor, was also expressed more highly in upper arm samples. Recently, foxc1 was shown to regulate the terminal differentiation of human keratinocytes (Bin et al., 2016), suggesting yet another potential epithelial difference between regenerating fore and upper limbs. Finally, $t b x 5$ is a transcription factor that specifies the identity of fore limb cells during limb development and is enriched in axolotl fore limb blastemal tissue during regeneration (Khan et al., 2002). We observed that after amputation, the expression of $t b \times 5$ decreased similarly in fore and upper arm samples, consistent with cellular dedifferentiation. However, higher $t b \times 5$ was observed in upper arm samples after this time, suggesting an earlier specification of fore limb identity in proximal amputations. This is suggestive of a mechanism that may normalize the offset timing of regeneration between fore and upper arm amputations.

Several genes were expressed more highly in fore arm samples, including cystatin a (csta) and distal-less homeobox 6 ( $d l_{x} 6$ ) (Fig. 8). Interestingly, $d l_{x} 6$ is expressed in the distal apical epidermal ridge of developing limbs of mice (Robledo et al., 2002) and dlx $6 \mathrm{mRNA}$ is distally enriched in zebrafish caudal fin (Rabinowitz et al., 2017). csta is a keratinocyte 
protein that plays a role in epidermal development and maintenance, likely through cell-cell adhesion interactions with desmogleins (Gupta et al., 2015). We note that $d s g 4$ was expressed more highly in fore arms and was identified as retinoic-acid responsive (see below).

\subsection{Transcriptional similarities to RA-induced limb proximalization}

Retinoic acid administration during the early stages of regeneration reprograms distal blastemas to a proximal state (Maden, 1982). A gene expression analysis using the same microarray in this study was performed recently to identify genes that were expressed during retinoic-acid induced limb proximalization (Nguyen et al., 2017). Of the 533 genes found to be significantly changed in the RA-proximalization study, 43 were also found to be significantly changed in this study (Supplemental File 3). At 20 DPA, the two gene lists showed highly correlated gene expression patterns $(R=0.82)$ with only two genes exhibiting expression in opposite directions. Seven of these genes showed $>2$ fold higher expression in upper arm and RA treated samples versus fore arm samples (aggrecan, brevican, keratin 19, indolethylamine $\mathrm{N}$-methyltransferase, tcaf1, uroplakin 3 a, and fatty acid binding protein 2) and 12 genes with $\geq 2$ fold lower expression in upper arm and RA treated samples versus fore arm samples (2 probes with no annotation, toll like receptor 2, dsg4, gap junction protein beta 6, prolactin releasing hormone, riddle 2, protein phosphatase 1 regulatory inhibitor subunit 14C, krt14/17-like, krt5, transglutaminase 1). Interestingly, none of these genes is a transcription factor and most are associated with cell stiffness, cell migration, epithelia, and ECM components. This supports the idea that proximal and distal blastema cells have different cell adhesion properties (Nardi and Stocum, 1983; Crawford and Stocum, 1988) and further emphasize the strong signal of epithelial and ECM differences identified in this study.

\section{Conclusions}

We identified genes that were expressed differently between regenerating upper and lower arms using two highly powered gene expression datasets. We reasoned that differently expressed genes might reveal mechanisms underlying the difference in regenerative rate between proximal and distal amputations, and positional information in cells during limb regeneration. We discovered early gene expression differences that suggest upper arms undergo more robust tissue remodeling and cell proliferation responses after amputation. These differences provide an explanation for why the overall time to complete regeneration is similar for proximal and distal amputations. Later in the regeneration program we identified genes that may contribute to proximal-distal differences in regeneration rate through their effects on cell proliferation and differentiation. The differently expressed epithelial proteins discovered between fore and upper arm samples predicts proximal-distal variation in the structure and function of the wound epidermis. Finally, we identified dynamic, bivariate transcriptional patterns of genes, some of which have unknown functions in amphibian epithelia or are predicted to contribute gelatinous and filamentous components to the ECM during regeneration. These complex patterns of gene expression implicate transcriptional control as a property that not only explains regenerative rate differences between proximal and distal locations of the limb axis but my also directly or indirectly 
inform positional information among local progenitor cells. To understand the significance of transcriptional control during salamander limb regeneration will likely require even finer temporal and spatial sampling.

\section{Supplementary Material}

Refer to Web version on PubMed Central for supplementary material.

\section{Acknowledgments}

This research was funded by the National Institutes of Health and Army Research Office through their support of the Salamander Genome Project (R24OD010435; 56157-LS-MUR) and Ambystoma Genetic Stock Center (P40OD019794; W911NF1410165), and by the National Science Foundation (1558017, 1656429). The contents of this paper are solely the responsibility of the authors and do not necessarily represent the official views of the ARO, $\mathrm{NIH}$, or NSF.

\section{References}

Aries IM, Jerchel IS, van den Dungen RE, van den Berk LC, Boer JM, Horstmann MA, Escherich G, Pieters R, den Boer ML. EMP1, a novel poor prognostic factor in pediatric leukemia regulates prednisolone resistance, cell proliferation, migration and adhesion. Leukemia. 2014; 28:1828-1837. [PubMed: 24625531]

Bals R, Wang X, Zasloff M, Wilson JM. The peptide antibiotic LL-37/hCAP-18 is expressed in epithelia of the human lung where it has broad antimicrobial activity at the airway surface. Proc Natl Acad Sci U S A. 1998; 95:9541-9546. [PubMed: 9689116]

Bidaux G, Borowiec AS, Prevarskaya N, Gordienko D. Fine-tuning of eTRPM8 expression and activity conditions keratinocyte fate. Channels. 2016; 10:320-331. [PubMed: 27014839]

Bin L, Deng L, Yang H, Zhu L, Wang X, Edwards MG, Richers B, Donald YM, Leung DYM. Bin forkhead box c1 regulates human primary keratinocyte terminal differentiation. PLoS One. 2016; 11:e0167392. [PubMed: 27907090]

Bord S, Horner A, Hembry RM, Compston JE. Stromelysin-1 (MMP-3) and stromelysin-2 (MMP-10) expression in developing human bone: potential roles in skeletal development. Bone. 1998; 23:7-12. [PubMed: 9662124]

Bryant DM, Johnson K, DiTommaso T, Tickle T, Couger MB, Payzin-Dogru D, Lee TJ, Leigh ND, Kuo TH, Davis FG, Bateman J, Bryant S, Guzikowski AR, Tsai SL, Coyne S, Ye WW, Freeman RM Jr, Peshkin L, Tabin CJ, Regev A, Haas BJ, Whited JL. A Tissue-Mapped Axolotl De Novo Transcriptome Enables Identification of Limb Regeneration Factors. Cell Reports. 2017; 18:762776. [PubMed: 28099853]

Bryant SV, Gardiner DM. The relationship between growth and pattern formation. Regeneration. 2016; 3:103-22. [PubMed: 27499882]

da Silva SM, Gates PB, Brockes JP. The newt ortholog of CD59 is implicated in proximodistal identity during amphibian limb regeneration. Dev Cell. 2002; 3:547-555. [PubMed: 12408806]

Echeverri K, Tanaka EM. Proximodistal patterning during limb regeneration. Dev Biol. 2005; 279:391-401. [PubMed: 15733667]

Ferreira F, Luxardi G, Reid B, Zhao M. Early bioelectric activities mediate redox-modulated regeneration. Development. 2016; 143:4582-4594. [PubMed: 27827821]

Furlow JD, Berry DL, Wang Z, Brown DD. A set of novel tadpole specific genes expressed only in the epidermis are down-regulated by thyroid hormone during Xenopus laevis metamorphosis. Dev Biol. 1997; 182:284-298. [PubMed: 9070328]

Gross J, Lapiere CM. Collagenolytic activity in amphibian tissues: a tissue culture assay. Proc Natl Acad Sci U S A. 1962; 48:1014-22. [PubMed: 13902219]

Knox SM, Lombaert IM, Reed X, Vitale-Cross L, Gutkind JS, Hoffman MP. Parasympathetic innervation maintains epithelial progenitor cells during salivary organogenesis. Science. 2010; 329:1645-1647. [PubMed: 20929848] 
Kumar A, Godwin JW, Gates PB, Garza-Garcia AA, Brockes JP. Molecular basis for the nerve dependence of limb regeneration in an adult vertebrate. Science. 2007; 318:772-777. [PubMed: 17975060]

Iten L, Bryant SV. Forelimb regeneration from different levels of amputation in the newt, Notophthalmus viridescens. Wilhelm Roux Archiv. 1973; 173:263-282.

Kang J, Hu J, Karra R, Dickson AL, Tornini VA, Nachtrab G, Gemberling M, Goldman JA, Black BL, Poss KD. Modulation of tissue repair by regeneration enhancer elements. Nature. 2016; 532:201206. [PubMed: 27049946]

Gupta A, Nitoiu D, Brennan-Crispi D, Addya S, Riobo NA, Kelsell DP, Mahoney MG. Cell cycle- and cancer-associated gene networks activated by Dsg2: evidence of cystatin A deregulation and a potential role in cell-cell adhesion. PLoS One. 2015; 10:e0120091. [PubMed: 25785582]

Khan P, Linkhart B, Simon HG. Different regulation of T-box genes Tbx4 and Tbx 5 during limb development and limb regeneration. Dev Biol. 2002; 250:383-92. [PubMed: 12376111]

Levin M. Molecular bioelectricity: how endogenous voltage potentials control cell behavior and instruct pattern regulation in vivo. Mol Biol Cell. 2014; 25:3835-3850. [PubMed: 25425556]

Maden M. Vitamin A and pattern formation in the regenerating limb. Nature. 1982; 295:672-675. [PubMed: 7057925]

McCusker CD, Athippozhy A, Diaz-Castillo C, Fowlkes C, Gardiner DM, Voss SR. Positional plasticity in regenerating Amybstoma mexicanum limbs is associated with cell proliferation and pathways of cellular differentiation. BMC Dev Biol. 2015; 15:45. [PubMed: 26597593]

McCusker CD, Gardiner DM. Understanding positional cues in salamander limb regeneration: implications for optimizing cell-based regenerative therapies. Dis Model Mech. 2014; 7:593-599. [PubMed: 24872456]

Monaghan JR, Epp LG, Putta S, Page RB, Walker JA, Beachy CK, Zhu W, Pao GM, Verma IM, Hunter T, Bryant SV, Gardiner DM, Harkins TT, Voss SR. Microarray and cDNA sequence analysis of transcription during nerve-dependent limb regeneration. BMC Biol. 2009; 7:1. [PubMed: 19144100]

Moriyasu M, Makanae A, Satoh A. Spatiotemporal regulation of keratin 5 and 17 in the axolotl limb. Dev Dyn. 2012; 241:1616-1624. [PubMed: 22836940]

Murray A, Sienerth AR, Hemberger M. Plet1 is an epigenetically regulated cell surface protein that provides essential cues to direct trophoblast stem cell differentiation. Sci Reports. 2016; 6:25112.

Mi H, Muruganujan A, Casagrande JT, Thomas PD. Large-scale gene function analysis with the PANTHER classification system. Nat Protocols. 2013; 8:1551-1566. [PubMed: 23868073]

Nardi JB, Stocum DL. Surface properties of regenerating limb cells: Evidence for gradation along the proximodistal axis. Differentiation. 1984; 25:27-31.

Nguyen M, Singhal P, Piet JW, Shefelbine SJ, Maden M, Voss SR, Monaghan JR. Retinoic acid receptor regulation of epimorphic and homeostatic regeneration in the axolotl. Development. 2017; 144:601-611. [PubMed: 28087637]

Niethammer P, Grabher C, Look AT, Mitchison TJ. A tissue-scale gradient of hydrogen peroxide mediates rapid wound detection in zebrafish. Nature. 2009; 459:996-999. [PubMed: 19494811]

Page RB, Monaghan JR, Walker JA, Voss SR. A model of transcriptional and morphological changes during thyroid hormone-induced metamorphosis of the axolotl. Gen Comp Endocrinol. 2009; 162:219-232. [PubMed: 19275901]

Pantalacci S, Gueguen L, Petit C, Lambert A, Peterkova R, Semon M. Transcriptomic signatures shaped by cell proportions shed light on comparative developmental biology. Genome Biol. 2017; 18:29. [PubMed: 28202034]

Phan AQ, Lee J, Oei M, Flath C, Hwe C, Mariano R, Vu T, Shu C, Dinh A, Simkin J, Muneoka K, Bryant SV, Gardiner DM. Position information in axolotl and mouse limb ECM is mediated via heparin sulfates and FGF during limb regeneration in the Axolotl (Ambystoma mexicanum). Regeneration. 2015; 4:182-201.

Rabinowitz JS, Robitaille AM, Wang Y, Ray CA, Thummel R, Gu H, Djukovic D, Raftery D, Berndt JD, Moon RT. Transcriptomic, proteomic, and metabolomic landscape of positional memory in the caudal fin of zebrafish. Proc Natl Acad Sci U S A. 2017; 114:E717-E726. [PubMed: 28096348] 
Rieger S, Sagasti A. Hydrogen peroxide promotes injury-induced peripheral sensory axon regeneration in the zebrafish skin. PLoS Biol. 2011; 9:e1000621. [PubMed: 21629674]

Robledo RF, Rajan L, Li X, Lufkin T. The Dlx5 and Dlx6 homeobox genes are essential for craniofacial, axial, and appendicular skeletal development. Genes Dev. 2002; 16:1089-101. [PubMed: 12000792]

Santosh N, Windsor LJ, Mahmoudi BS, Li B, Zhang W, Chernoff EA, Rao N, Stocum DL, Song F. Matrix metalloproteinase expression during blastema formation in regeneration-competent versus regeneration-deficient amphibian limbs. Dev Dyn. 2011; 240:1127-41. [PubMed: 21128310]

Schindelin J, Arganda-Carreras I, Frise E, Kaynig V, Longair M, Pietzsch T, Preibisch S, Rueden C, Saalfeld S, Schmid B, Tinevez JY, White DJ, Hartenstein V, Eliceiri K, Tomancak P, Cardona A. Fiji: an open-source platform for biological-image analysis. Nat Methods. 2012; 9:676-682. [PubMed: 22743772]

Schmidt K, Hughes C, Chudek JA, Goodyear SR, Aspden RM, Talbot R, Gundersen TE, Blomhoff R, Henderson C, Wolf CR, Tickle C. Cholesterol metabolism: the main pathway acting downstream of cytochrome P450 oxidoreductase in skeletal development of the limb. Mol Cell Biol. 2009; 29:2716-2729. [PubMed: 19273610]

Sousounis K, Looso M, Maki N, Ivester CJ, Braun T, Tsonis PA. Transcriptome analysis of newt lens regeneration reveals distinct gradients in gene expression patterns. PLoS ONE. 2013; 8:e61445. [PubMed: 23613853]

Stellmach VM, Fuchs E. Exploring the mechanisms underlying cell type-specific and retinoidmediated expression of keratins. The New Biologist. 1989; 1:305-317. [PubMed: 2484828]

Stocum DL. The relation of mitotic index, cell density, and growth to pattern regulation in regenerating Ambystoma maculatum forelimbs. J Exp Zool. 1980; 212:233-242.

Tetlow LC, Adlam DJ, Woolley DE. Matrix metalloproteinase and proinflammatory cytokine production by chondrocytes of human osteoarthritic cartilage: associations with degenerative changes. Arthritis Rheum. 2001; 44:585-594. [PubMed: 11263773]

Velez-delValle C, Marsch-Moreno M, Castro-Munozledo F, Galvan-Mendoza IJ, Kuri-Harcuch W. Epithelial cell migration requires the interaction between the vimentin and keratin intermediate filaments. Sci Reports. 2016; 6:24389.

Voss SR, Palumbo A, Nagarajan R, Gardiner DM, Muneoka K, Stromberg AJ, Athippozhy AT. Gene expression during the first 28 days of axolotl limb regeneration I: Experimental design and global analysis of gene expression. Regeneration. 2015; 2:120-136. [PubMed: 27168937]

Comp Biochem Physiol C Toxicol Pharmacol. Author manuscript; available in PMC 2019 June 01. 


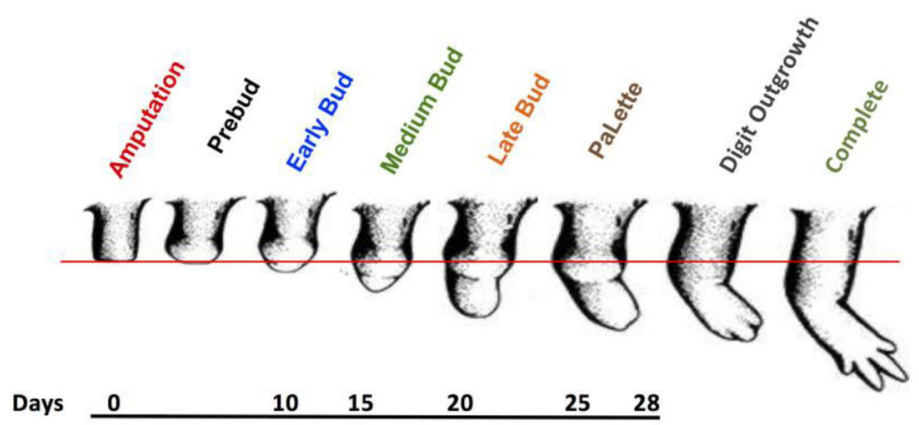

$1 \mathrm{~mm}$

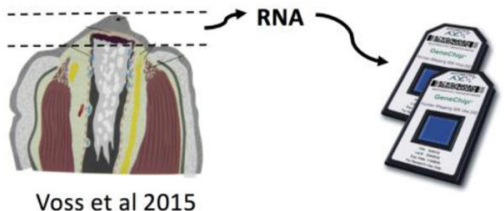

398 Gene Chip Study

20 time points

8-10 replicates per time point

Voss et al 2015

2 amputation planes

Fig. 1.

Cartoon showing stages of limb regeneration relative to time after amputation, and an overview of the experimental design. 

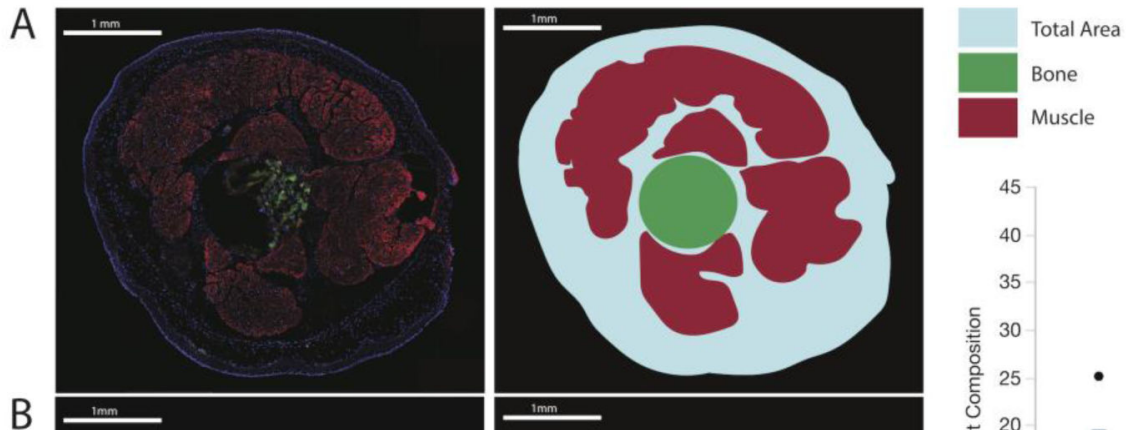

$\mathrm{B}$
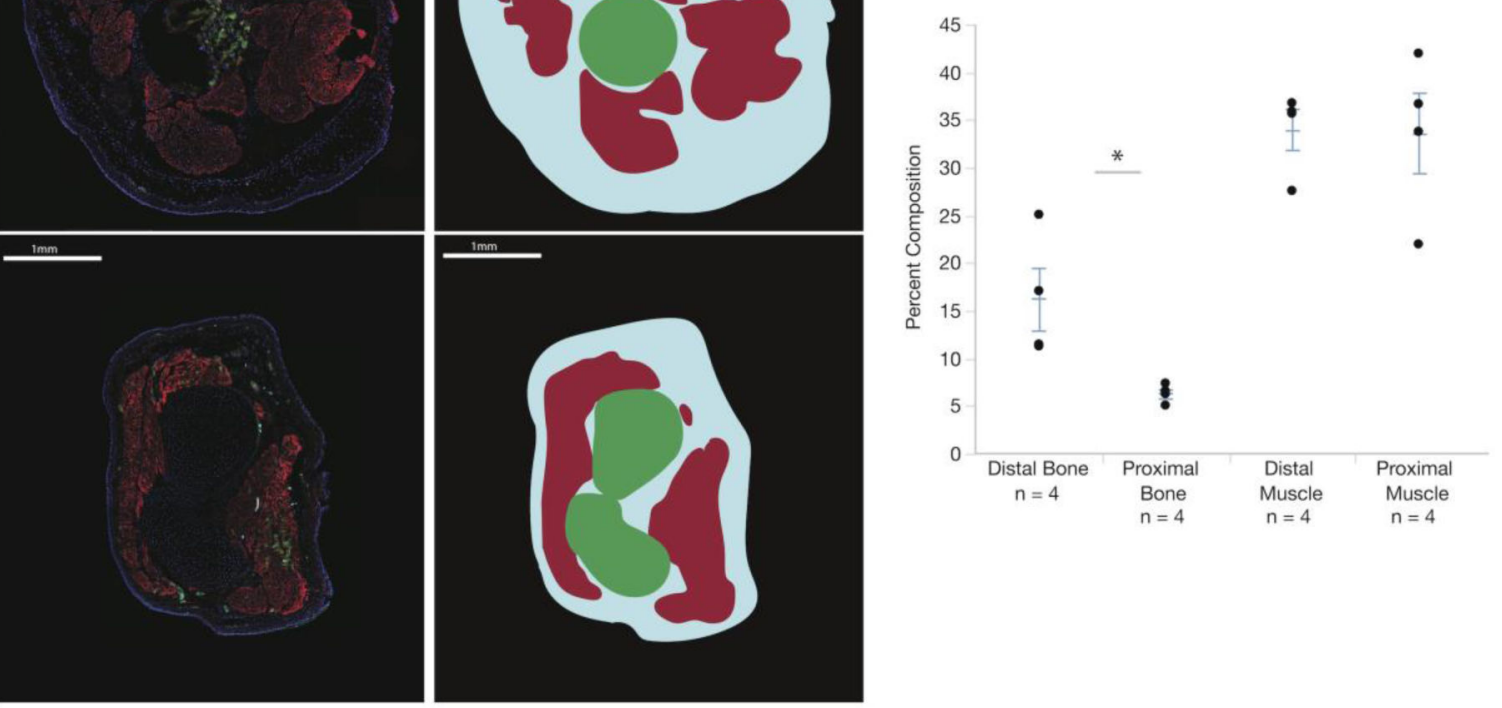

Fig. 2.

Histology of axolotl forearm and upper arm. (A) Tissue was collected from intact limbs at the same position that tissues were collected for microarray analysis of upper and fore arms. Red staining indicates muscle staining and blue indicates nuclear staining. Green fluorescence seen in A is fragmented calcified bone, as calcified bone exhibits autofluorescence in the green channel. Osteocytes were identified and bone area was calculated by histological identification. Skeletal structures and muscle was traced and calculated as a percentage of the total area using ImageJ. Calculated area is represented as corresponding colors in the figure legend. (B) Calculated area $(n=4)$ distribution for each limb sampled. Samples passed a Levine's test for equal variance and only the area of bone was significantly different between fore and upper limbs using a student's T test with equal variance $(\mathrm{p}=0.021)$. 
myh1

8

6

4

2

0

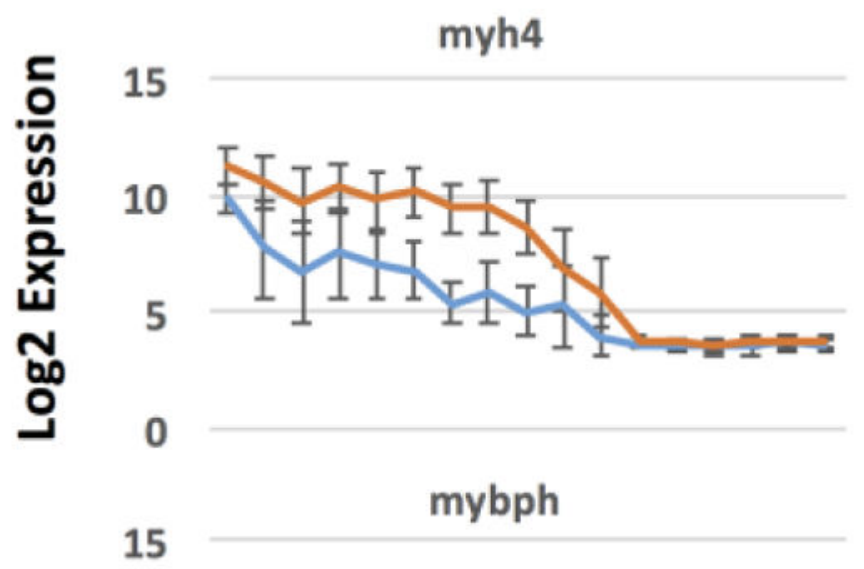

10

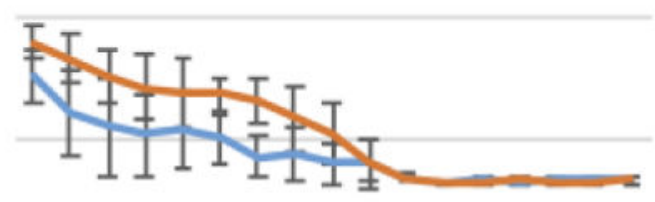

0

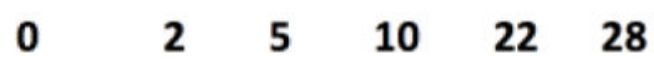

15

tpm1

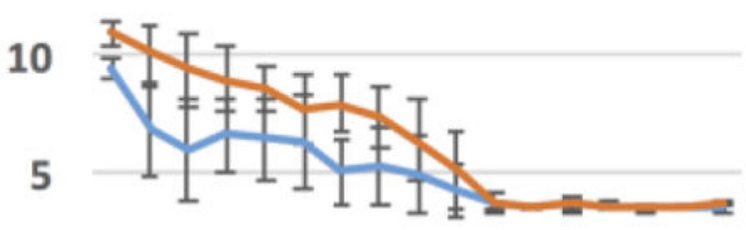

0
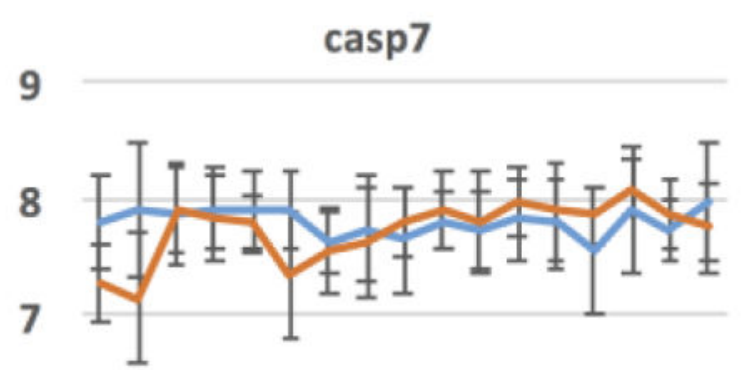

6

15

smyd1

10

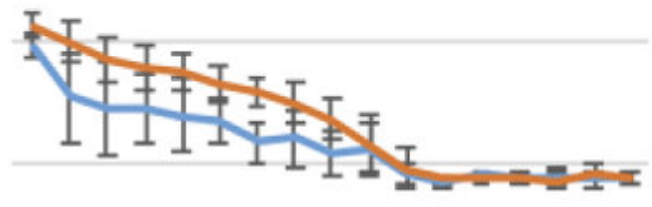

0

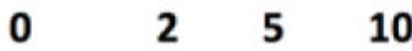

$22 \quad 28$

\section{Days Post Amputation}

Fig. 3.

Example expression profiles for muscle-associated genes that were expressed differently between fore (orange) and upper (blue) arm samples at the time of amputation and during the first 10 days of regeneration. Error bars are standard deviations of the mean. 
12

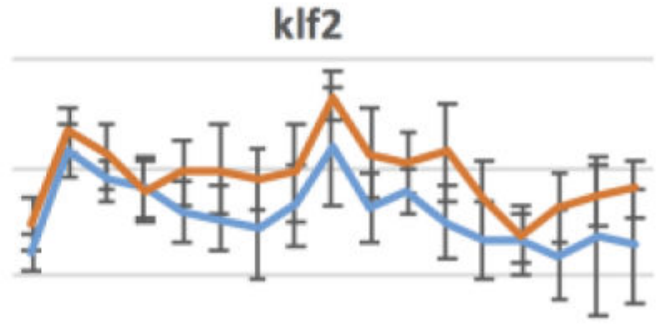

6

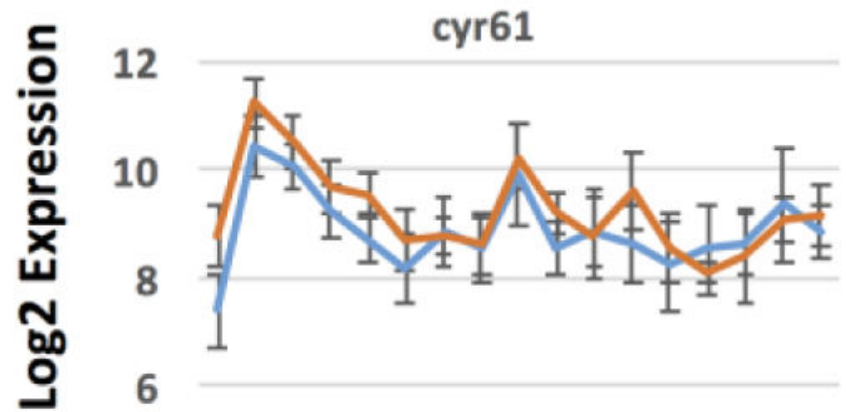

fos

11

9

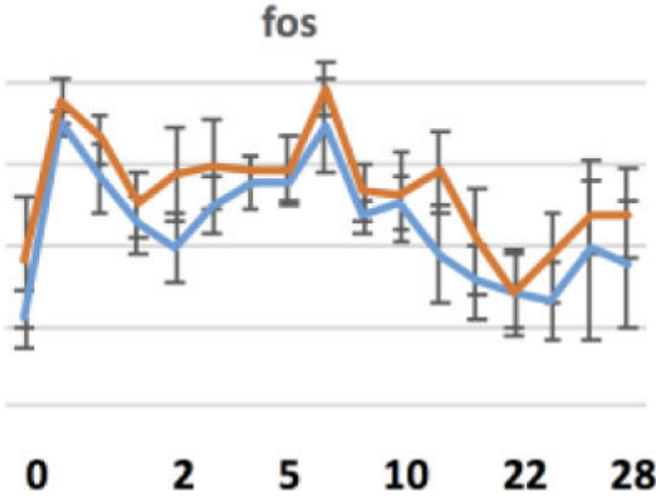

12

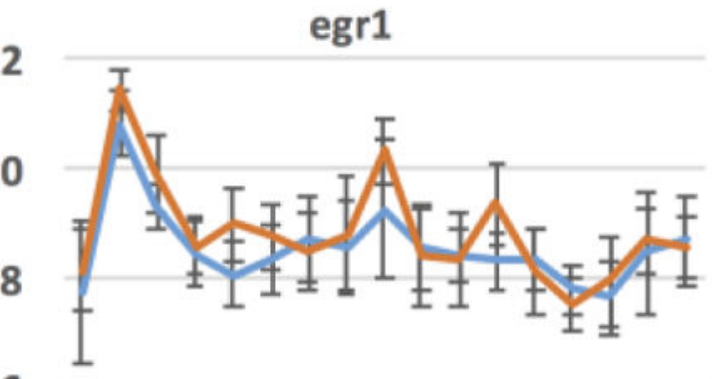

6

11

meis2

10

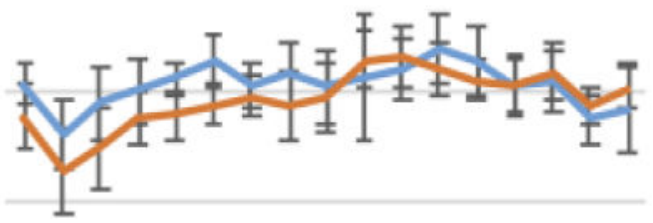

8

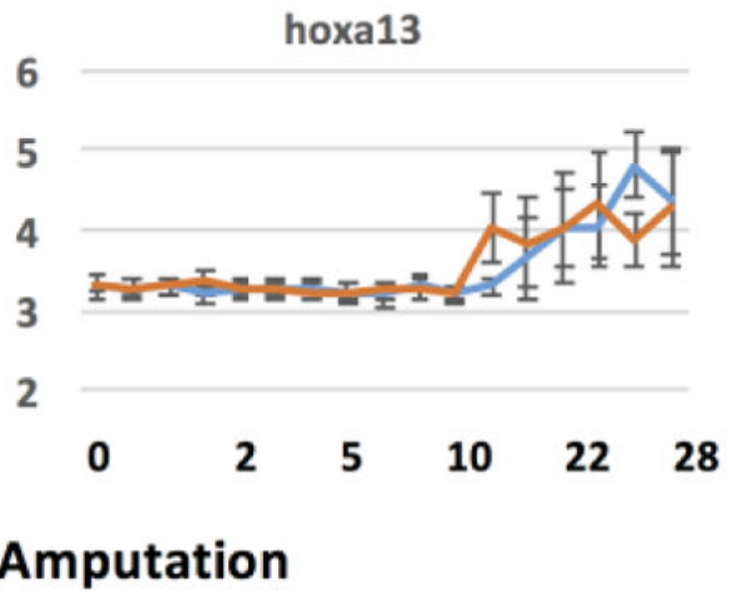

Fig. 4.

Gene expression profiles for early immediate genes (klf2, cyr61, fos, egr 1 ) and two transcription factors (meis2, hoxa13) that were expressed differently between fore (orange) and upper (blue) arm samples during regeneration. Of these genes, only klf2, fos, and cyr61 exhibited a 2-fold expression difference at one or more of the time intervals investigated. See Supplemental File 2 for the specific intervals of time that genes were expressed differently. Error bars are standard deviations of the mean. 
12

chrdl1

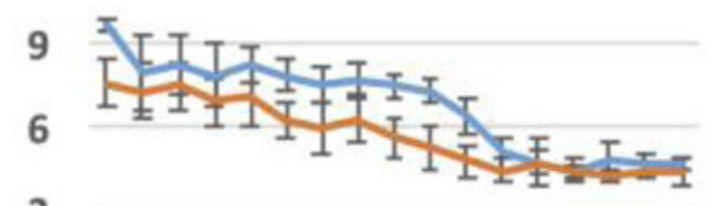

3

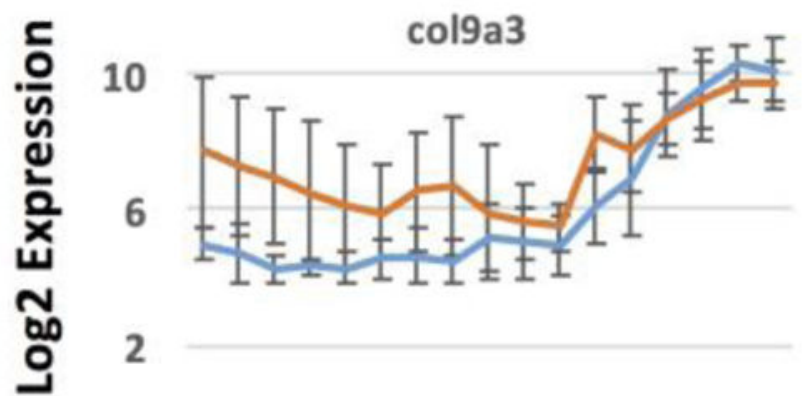

12

lect1

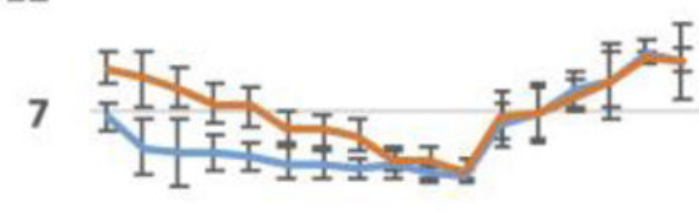

2

0

\section{5}

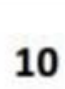

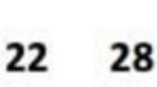

13

umod

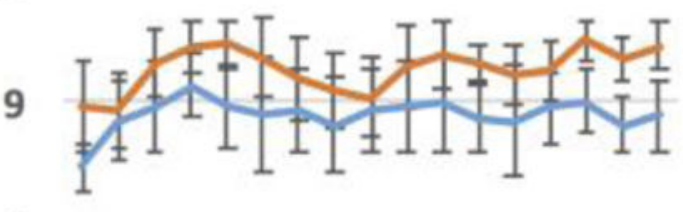

5

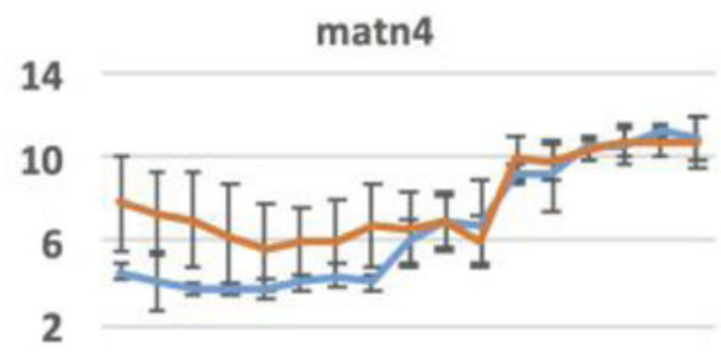

12

thd120 (X. laevis)

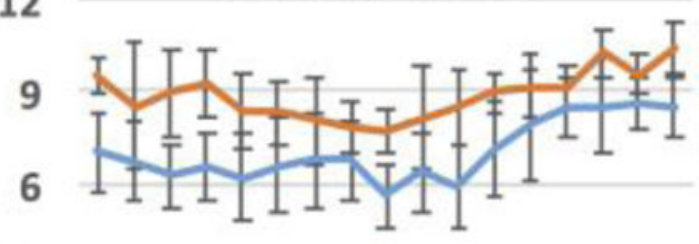

3

$22 \quad 28$

Fig. 5.

Gene expression profiles for some of the extracellular matrix-associated genes that were expressed differently between fore (orange) and upper (blue) arm samples at the time of amputation and during regeneration. See Supplemental File 2 for the specific intervals of time that genes were expressed differently. Error bars are standard deviations of the mean. 


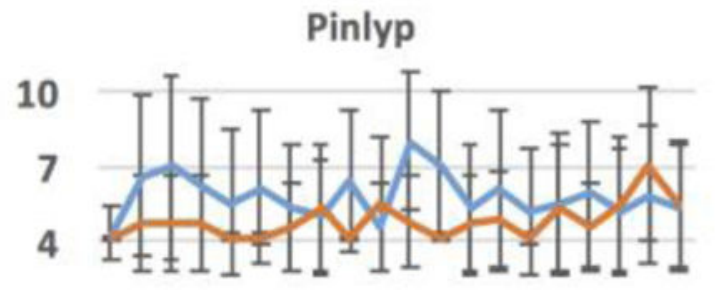

1
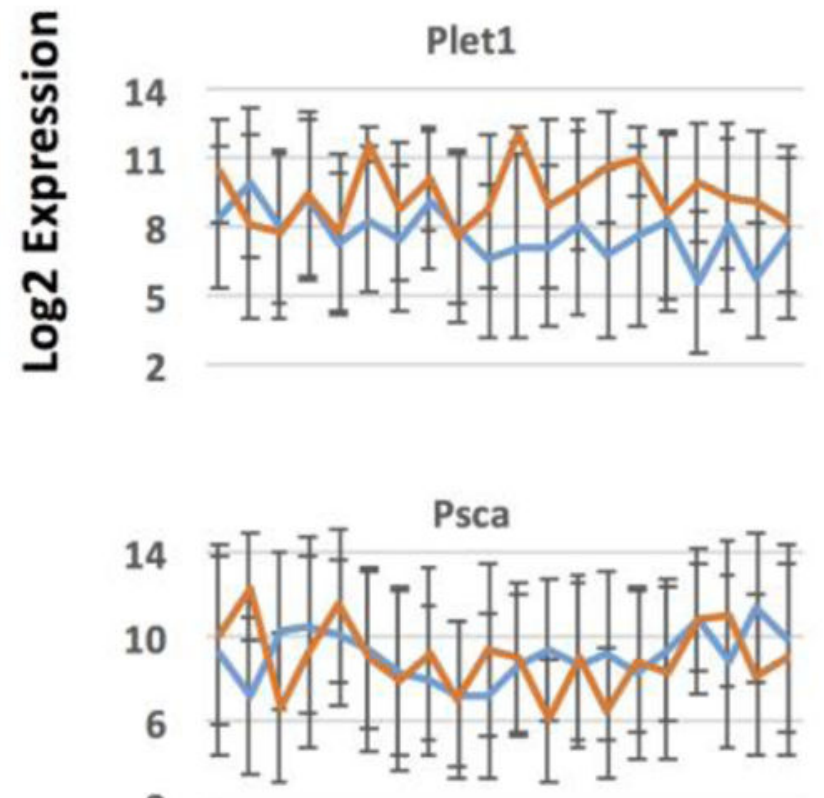

2

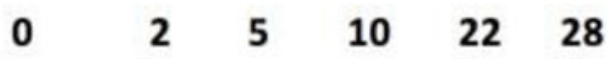

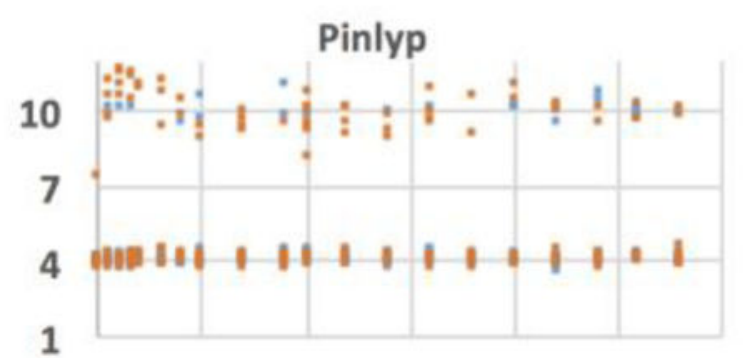
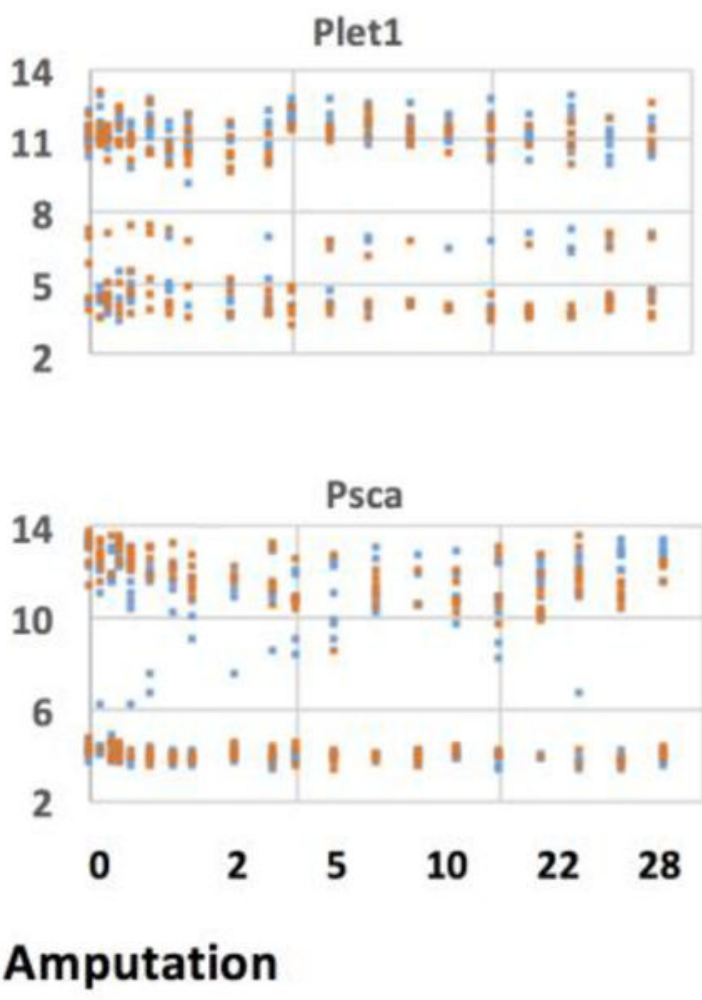

Fig. 6.

Gene expression profiles for some of the genes that showed bivariate (pinlyp, psca), and in one case trivariate (plet1), expression profiles. The left panels show the mean expression values for fore (orange) and upper (blue) arm samples throughout regeneration. Error bars are standard deviations of the mean. The right panels show expression values obtained from each replicate microarray. 

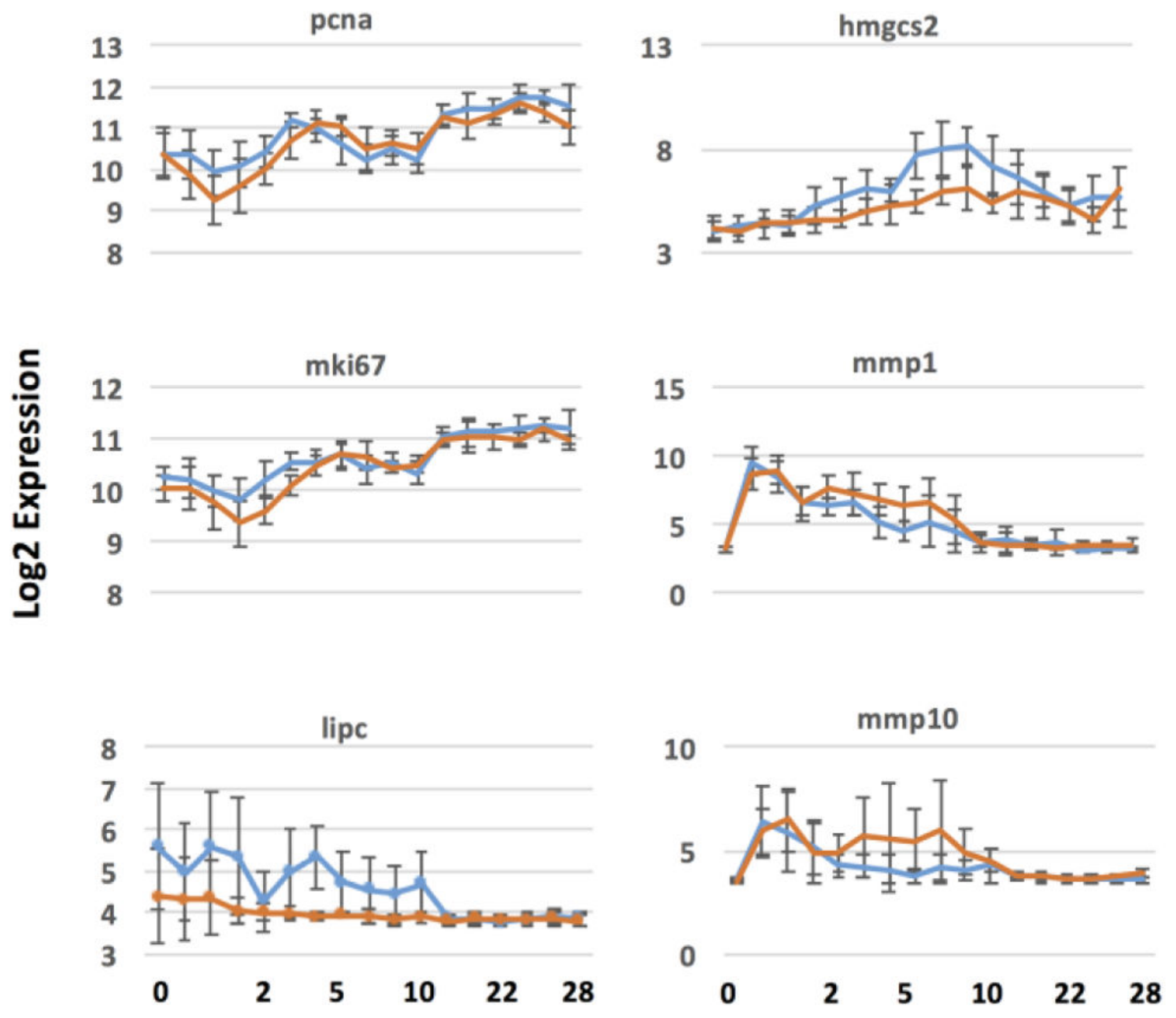

\section{Days Post Amputation}

Fig. 7.

Example expression profiles for cell-cycle (pcna, mki67), lipid metabolic (lipc, hmgcs2) and matrix metalloproteinase ( $\mathrm{mmp1}, \mathrm{mmp} 10$ ) genes that were expressed differently between fore (orange) and upper (blue) arm samples for the 3-9 DPA time interval. Error bars are standard deviations of the mean. 
10

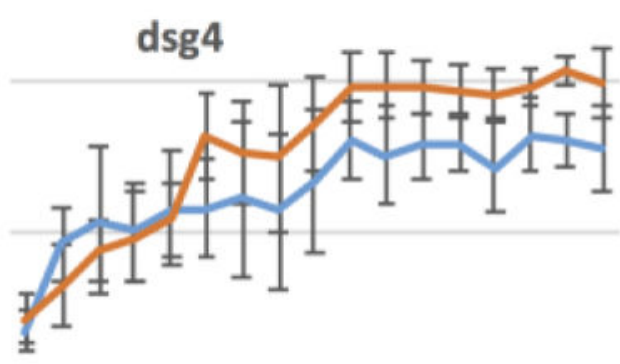

2
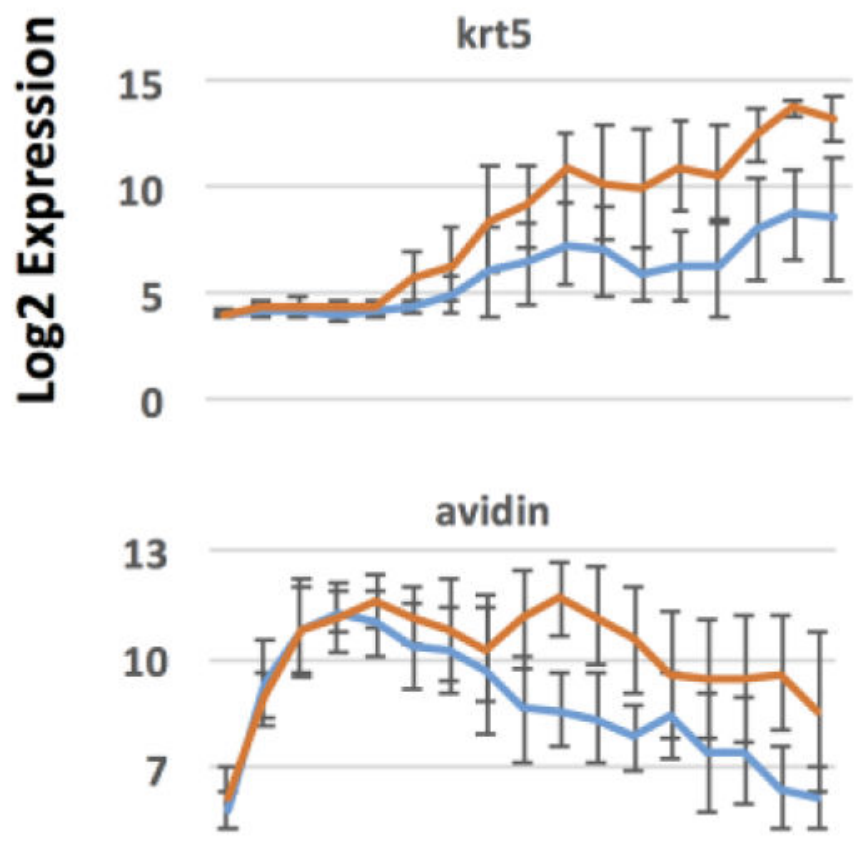

4

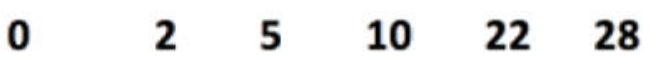

10

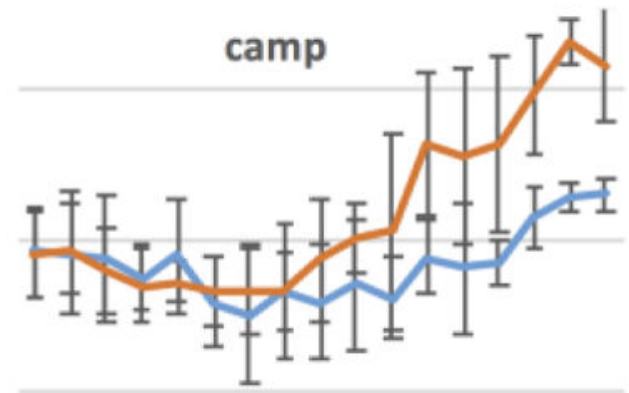

2
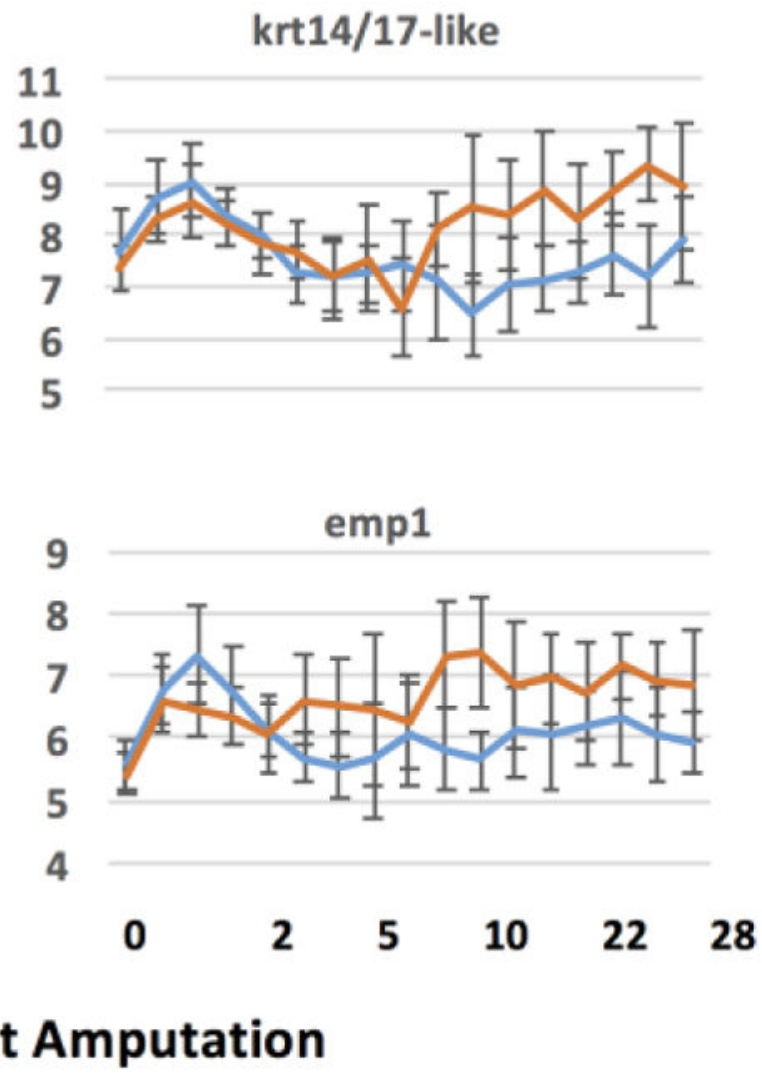

Fig. 8.

Example expression profiles for epithelia-associated genes that were expressed differently between fore (orange) and upper (blue) arm samples at 10 DPA. See Supplemental File 2 for the specific intervals of time that genes were expressed differently. Error bars are standard deviations of the mean. 
tcaf1
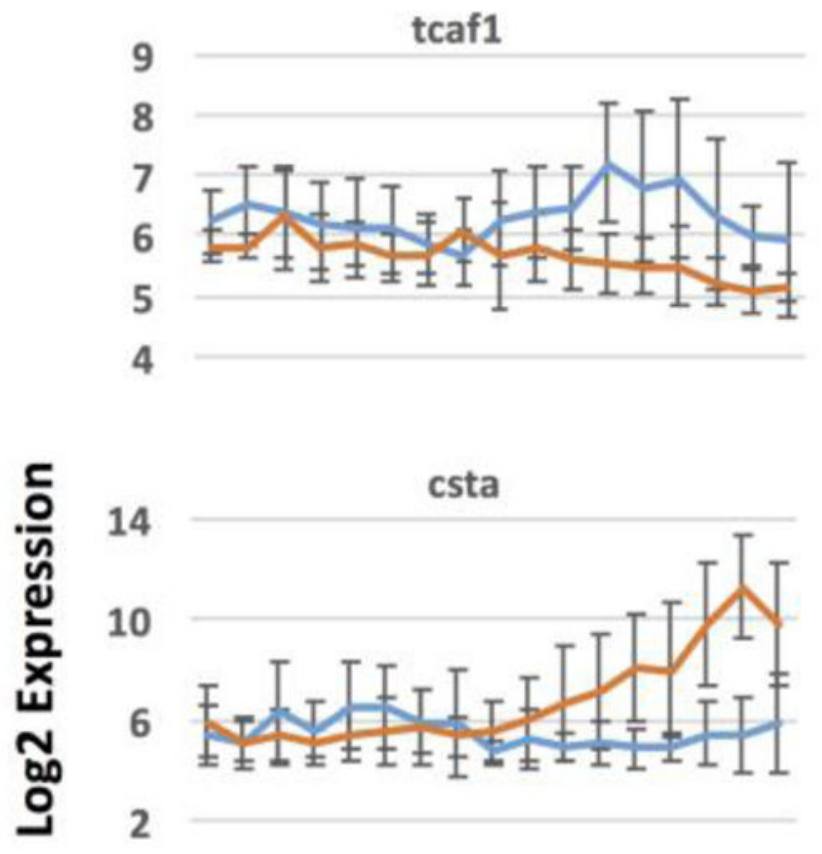

lep

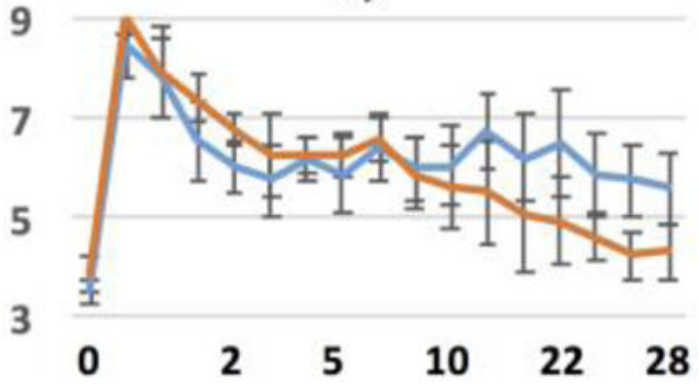

10

foxc1
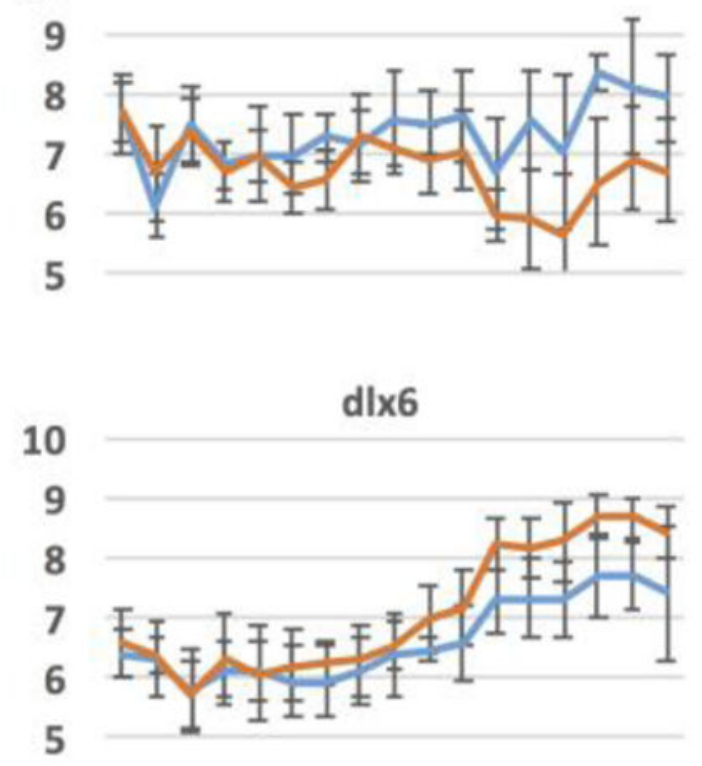

tbx5

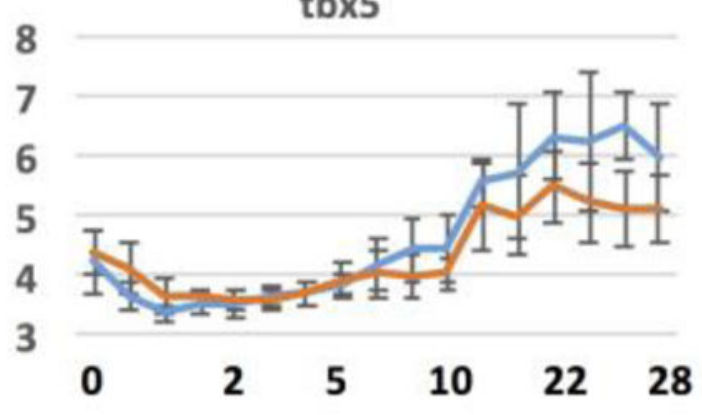

Days Post Amputation

Fig. 9.

Example expression profiles for genes that were expressed differently between fore (orange) and upper (blue) arm samples for the 18-28 DPA time interval. See Supplemental File 2 for the specific intervals of time that genes were expressed differently. Error bars are standard deviations of the mean. 


\section{Table 1}

Gene Ontology and Pathway terms that were significantly enriched using all genes that were differentially expressed between fore and upper arm samples.

\begin{tabular}{lrll} 
PANTHER Protein Class & \# Genes & Enrichment & P-value \\
\hline actin binding motor protein & 16 & 11.58 & $3.33 \mathrm{E}-10$ \\
intermediate filament & 9 & 7.89 & $5.88 \mathrm{E}-04$ \\
structural protein & 14 & 5.98 & $3.16 \mathrm{E}-05$ \\
actin family cytoskeletal protein & 41 & 5.62 & $2.08 \mathrm{E}-16$ \\
extracellular matrix glycoprotein & 12 & 5.40 & $6.78 \mathrm{E}-04$ \\
extracellular matrix protein & 21 & 4.86 & $9.53 \mathrm{E}-07$ \\
cell junction protein & 13 & 4.65 & $1.31 \mathrm{E}-03$ \\
protease inhibitor & 10 & 4.32 & $2.72 \mathrm{E}-02$ \\
cytoskeletal protein & 54 & 3.77 & $1.53 \mathrm{E}-14$ \\
cell adhesion molecule & 14 & 3.70 & $7.23 \mathrm{E}-03$ \\
signaling molecule & 26 & 2.16 & $4.55 \mathrm{E}-02$
\end{tabular}

PANTHER GO-Slim Biological Process

$\begin{array}{llll}\text { muscle contraction } & 40 & 12.45 & 3.12 \mathrm{E}-28 \\ \text { blood circulation } & 14 & 8.80 & 3.36 \mathrm{E}-07 \\ \text { muscle organ development } & 23 & 5.89 & 5.23 \mathrm{E}-09 \\ \text { cellular component morphogenesis } & 45 & 5.06 & 2.27 \mathrm{E}-16 \\ \text { mesoderm development } & 29 & 4.64 & 3.60 \mathrm{E}-09 \\ \text { sensory perception } & 17 & 4.53 & 8.97 \mathrm{E}-05 \\ \text { ectoderm development } & 18 & 3.43 & 1.97 \mathrm{E}-03 \\ \text { cell differentiation } & 19 & 3.09 & 4.65 \mathrm{E}-03 \\ \text { cell adhesion } & 19 & 2.96 & 8.25 \mathrm{E}-03 \\ \text { developmental process } & 74 & 2.54 & 1.92 \mathrm{E}-11\end{array}$

PANTHER GO-Slim Cellular Component

$\begin{array}{lrrl}\text { intermediate filament cytoskeleton } & 9 & 9.99 & 2.60 \mathrm{E}-05 \\ \text { actin cytoskeleton } & 30 & 7.24 & 5.03 \mathrm{E}-15 \\ \text { extracellular matrix } & 21 & 7.21 & 2.54 \mathrm{E}-10 \\ \text { cell junction } & 12 & 7.01 & 1.40 \mathrm{E}-05 \\ \text { cytoskeleton } & 40 & 4.72 & 5.41 \mathrm{E}-14 \\ \text { extracellular region } & 30 & 3.65 & 1.14 \mathrm{E}-07\end{array}$

PANTHER GO-Slim Molecular Function

$\begin{array}{llll}\text { motor activity } & 16 & 5.73 & 6.32 \mathrm{E}-06 \\ \text { constituent of cytoskeleton } & 43 & 4.16 & 9.28 \mathrm{E}-13 \\ \text { actin binding } & 12 & 4.08 & 9.01 \mathrm{E}-03 \\ \text { structural molecule activity } & 63 & 3.60 & 2.00 \mathrm{E}-16 \\ \text { cytoskeletal protein binding } & 17 & 3.52 & 1.79 \mathrm{E}-03 \\ \text { protein binding } & 78 & 1.74 & 1.18 \mathrm{E}-04 \\ \text { Reactome Pathways } & & & \\ \text { Striated muscle contraction } & 29 & 27.59 & 9.37 \mathrm{E}-29\end{array}$

Comp Biochem Physiol C Toxicol Pharmacol. Author manuscript; available in PMC 2019 June 01. 


\begin{tabular}{lrll} 
PANTHER Protein Class & \# Genes & Enrichment & P-value \\
\hline Activation of MMPs & 7 & 12.95 & $2.70 \mathrm{E}-03$ \\
Collagen degradation & 14 & 10.84 & $1.68 \mathrm{E}-07$ \\
Muscle contraction & 42 & 10.28 & $1.18 \mathrm{E}-25$ \\
Smooth Muscle Contraction & 7 & 9.32 & $2.25 \mathrm{E}-02$ \\
ECM proteoglycans & 15 & 8.32 & $1.30 \mathrm{E}-06$ \\
Degradation of ECM & 22 & 8.05 & $2.63 \mathrm{E}-10$ \\
Collagen formation & 11 & 5.81 & $7.57 \mathrm{E}-03$ \\
ECM organization & 33 & 5.36 & $1.92 \mathrm{E}-11$ \\
\hline
\end{tabular}

